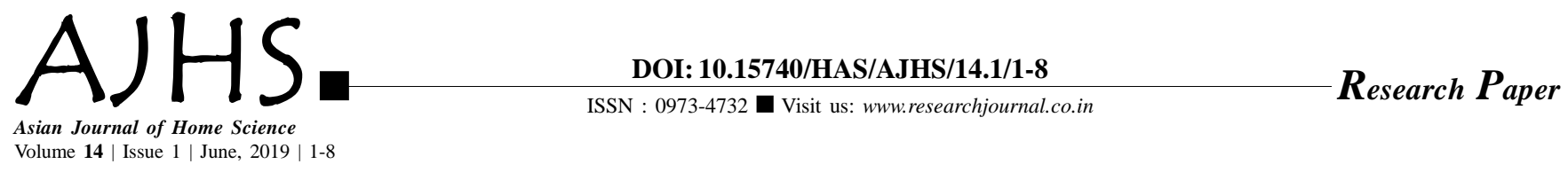

\title{
Traditional costumes of Lambadi and Koya tribes of Andhra Pradesh
}

\section{Godi Sindhu and Shahnaz Jahan}

Received: 27.06.2018; Revised: 01.04.2019; Accepted: 10.04.2019

See end of the paper for authors' affiliations

\section{Godi Sindhu}

Department of Clothing and Textiles, College of Home

Science, G.B. Pant University of Agriculture and Technology,

Pantnagar (Uttarakhand) India Email : sindu.godi@gmail.com
ABSTRACT : The Lambadi and Koya tribes are the major tribal communities of Andhra Pradesh. The racial inheritance of Lambadi and Koya tribes are enhanced with diverse colorful cultural constituents. The distinctiveness of these tribes was extremely noted in their traditional and folk cultures. The traditional costumes of any community or tribe can be affected by the development and change of time. Therefore, the research was undertaken to restore the information of traditional costumes of Lambadi and Koya tribes of Andhra Pradesh through documentation, before it gets completely diminished. So that one can get detailed information regarding the traditional costumes and textiles used by the tribes of Andhra Pradesh to create new designs for costumes and textiles.

KEY WORDS: Lambadi, Koya, Costumes, Female, Male

- HOW TO CITE THIS PAPER : Sindhu, Godi and Jahan, Shahnaz (2019). Traditional costumes of Lambadi and Koya tribes of Andhra Pradesh. Asian J. Home Sci., 14 (1) : 1-8, DOI: 10.15740/HAS/AJHS/ 14.1/1-8. Copyright@ 2019: Hind Agri-Horticultural Society. 